\title{
PRODUÇÃO DO CONHECIMENTO SOBRE O SISTEMA ELETRÔNICO DE EDITORAÇÃO DE REVISTAS (SEER) NO BRASIL NOS ANOS DE 2003 A 2010
}

\author{
Maria Helena Machado de Moraes ${ }^{\mathrm{i}}$ \\ Angélica Conceição Dias Miranda ${ }^{\text {ii }}$
}

\begin{abstract}
Resumo: O processo de editoração das produções científicas beneficia-se na contemporaneidade com a editoração eletrônica. Esta agiliza o processo, reduz custos e divulga mundialmente as publicações científicas das instituições. No Brasil foi disponibilizado pelo Instituto Brasileiro de Informação em Ciências e Tecnologia (IBICT) o Sistema Eletrônico de Editoração de Revistas (SEER) cujo propósito é colaborar para a disseminação do conhecimento produzido. O objetivo principal deste estudo é avaliar a produção do conhecimento sobre o SEER no Brasil nos anos de 2003 a 2010, busca investigar, analisar, descrever e apresentar quantitativamente os resultados encontrados. A pesquisa foi realizada nas revistas eletrônicas de Biblioteconomia que utilizam o sistema para disponibilizar suas publicações. A referida plataforma é vista como um gerenciador de publicações científicas que faz da tecnologia uma ferramenta para suas propostas, tornando-se valioso para visibilidade das publicações científicas no Brasil.
\end{abstract}

Palavras-chave: Sistema Eletrônico de Editoração de Revistas (SEER). Open Journal System (OJS). Acesso aberto. Brasil.

\section{KNOWLEDGE MANAGEMENT ABOUT THE ELECTRONIC SYSTEM FOR JOURNAL PUBLISHING (SEER) IN BRAZIL AT THE YEARS 2003 TO 2010}

\begin{abstract}
The process of publishing scientific production, gives benefits from the contemporaneity with the desktop publishing. It streamlines the process, reduces costs and disseminate worldwide scientific publications of the institutions. In Brazil was released by the Brazilian Institute of Information Sciences and Technology IBICT, the Electronic System for Journal Publishing - SEER whose purpose is to collaborate in the dissemination of knowledge. The main objective of this study is to evaluate the production of knowledge about the SEER in Brazil during the years 2003 to 2010. It seeks to investigate, analyze, describe and present the findings quantitatively. The research was held in electronic journals that use of Library System to provide their publications. This platform is seen as a manager of scientific publications is a tool for technology their proposals, making it valuable for visibility of publications science in Brazil.
\end{abstract}

Keywords: Electronic System for Journal Publishing (SEER). Open Journal System (OJS). Free Access. Brazil.

\footnotetext{
${ }^{\mathrm{i}}$ Universidade Federal do Rio Grande. hmachmor@gmail.com.

ii Universidade Federal do Rio Grande. angelicacdm@gmail.com.

Recebido em: 23/02/2011; aceito para publicação em: 02/09/2011.
} 


\section{INTRODUÇÃO}

As tecnologias da informação contribuem para que a comunicação científica ocorra de maneira dinâmica, oportunizando melhor interação entre leitores, autores e seus pares. O processo de editoração das produções científicas realizado pelo método manual, que dependia de tempo, de verba e limitava-se a espaço, como região ou país, beneficia-se na contemporaneidade com a editoração eletrônica.

No Brasil o Sistema Eletrônico de Editoração de Revistas (SEER) foi disponibilizado pelo Instituto Brasileiro de Informação em Ciências e Tecnologia (IBICT) com vistas a agilizar o processo, reduzir custos e divulgar mundialmente as publicações científicas das instituições.

Disponibilizado pela Brittish Columbia, no Canadá, e conhecido como Open Journal System (OJS), traduzido e customizado pelo IBICT, esse sistema, cujo sítio de acesso é http://seer.ibict.br/, visa atender a demanda das publicações on-line. Um dos seus principais pontos é ser gratuito, principalmente para as instituições públicas que dependem de recursos financeiros do governo. O SEER passou a ser implantado nas instituições do Brasil na última década, tornando o conhecimento produzido visível e de fácil acesso.

O SEER tem o propósito de colaborar para a disseminação do conhecimento produzido, ou seja, a explicitação e o compartilhamento através da sua comunicação. Por facilitar o acesso aberto, o sistema representa grande contribuição à sociedade. Sabe-se que o acesso aberto, movimento que está ocorrendo no mundo, oportuniza liberdade de uso das publicações científicas.

O objetivo principal deste estudo é avaliar a produção do conhecimento sobre o Sistema Eletrônico de Editoração de Revistas (SEER) no Brasil, nos anos de 2003 a 2010, buscando investigar, analisar, descrever e apresentar quantitativamente os resultados encontrados. Compreende-se a importância de conhecer a produção do conhecimento, assim como a iniciativa do acesso aberto, por conseguinte, buscaram-se conceitos na literatura que contribuam para o desenvolvimento do presente trabalho. Ressalta-se a relevância de conhecer os estudos realizados acerca do SEER, tanto para sua divulgação como para visibilizar a produção do conhecimento. 


\section{PRODUÇÃO DO CONHECIMENTO}

Entende-se que o conhecimento é produzido pelo homem a partir das experiências cotidianas, em seus estudos, pesquisas e nas atividades que realizam no desenvolvimento de seu trabalho. A inquietação é para que o conhecimento seja compartilhado, isto é, quem o domina consiga explicitar e cooperar com o aprendizado dos demais membros da sociedade.

Conhecimento é uma mistura fluída de experiência condensada, valores, informação contextual e insight experimentado, a qual proporciona uma estrutura para a avaliação e incorporação de novas experiências e informações. (DAVENPORT; PRUSAK, 2003, p. 6).

Observa-se a importância do estudo, da pesquisa e da publicação de seus resultados, disseminando, assim, para um público mais abrangente o que está sendo produzido na academia. Para Targino (2007, p. 98), "só é conhecimento a parcela dos elementos que se incorporam ao repertório cognitivo e conceitual do ser humano". Com as pesquisas visíveis, existe maior facilidade de leitura, e estimula-se o crescimento intelectual do ser humano.

O uso das tecnologias de informação e comunicação, permitem intercambiar conhecimentos e experiências à distancia com outros indivíduos, permitindo a assimilação de novos conhecimentos e habilidades. (VIDOTTI; VIEIRA, 2004, p. 41).

Compreende-se que, com o uso da tecnologia para disponibilizar as pesquisas, o acesso ao conhecimento é quase que imediato.

Cabe ressaltar a importância das discussões sobre o acesso aberto à produção do conhecimento, pois torna-se importante a visibilidade desses conteúdos, contribuindo para o desenvolvimento intelectual da sociedade.

\section{ACESSO ABERTO}

$\mathrm{O}$ acesso aberto às publicações científicas tem gerado inúmeras facilidades, tanto para leitores como para os autores. Os leitores podem fazer leituras, download, impressões, cópias e salvar o conteúdo em seu computador pessoal, facilitando o acesso a pesquisas e seus resultados. Para os autores é uma forma de tornar seu estudo público, isto é, estará visível para seus pares, podendo ser avaliado e citado por outros pesquisadores da área.

Para Leite (2009, p. 16), “O acesso aberto a resultados de pesquisa tem sido visto como fator que maximiza o acesso à pesquisa propriamente dita”. Pode-se compreender que a 
liberdade de acessar esses documentos, a qualquer momento e em qualquer local, facilita que o conhecimento seja compartilhado de forma gratuita, contemplando diversas pessoas ao mesmo tempo.

O número de citações dos trabalhos que estão acessíveis, em geral, é maior do que trabalhos restritos ou pagos, devido ao fato de estarem ao alcance de mais pessoas ao mesmo tempo. Vale ressaltar, no entanto, que os direitos autorais devem ser respeitados.

Devido à crescente discussão sobre acesso aberto, manifestos de apoio ao movimento foram criados, contemplando e valorizando o assunto. Kuramoto (2006, p. 96) descreve que "o movimento se baseia no princípio de que todos os resultados de pesquisas financiadas com recursos públicos devem ser de livre acesso". Espera-se, com esta iniciativa, que os pesquisadores sintam-se incitados a publicar suas pesquisas para a sociedade num todo, pois cada membro contribui, mesmo não ciente, para que os estudos ocorram.

\footnotetext{
O movimento de apoio aos open archives e ao acesso livre à informação surge em consequência das dificuldades encontradas pela comunidade científica mundial no acesso à informação científica. Concretizou-se, de fato, por meio de diversos manifestos, como as declarações de Bethesda, Budapeste e Berlim, além de manifestações de organizações não-governamentais e internacionais, como a Ifla e a OCDE, entre outras. (IBICT, 2005).
}

Com o uso das tecnologias vigentes, há sistemas que foram desenvolvidos para gerenciar as publicações eletrônicas e que incentivam o acesso aberto ao conhecimento, como o Sistema Eletrônico de Editoração de Revistas (SEER).

Kuramoto (2006, p. 93) comenta que "o acesso ao conhecimento científico continua sendo fundamental para o desenvolvimento científico e tecnológico de um país". O sistema contribui para que ocorra de maneira ampla o acesso às produções científicas eletrônicas e, assim, mais pessoas acompanham o desenvolvimento intelectual do país.

\section{SISTEMA ELETRÔNICO DE EDITORAÇÃO DE REVISTAS (SEER)}

Com as tecnologias voltadas para a demanda informacional, são desenvolvidos sistemas que visam atender as necessidades de organizar e gerenciar as publicações científicas.

As publicações eletrônicas estão visíveis, diferente do que acontecia no passado, em que o processo de publicação ocorria de forma lenta, manual e o conhecimento estava ao alcance de poucas pessoas (MEADOWS, 1999). Vive-se, atualmente, a explosão 
informacional, há mais informação ao alcance da sociedade, e diminuíram as barreiras de tempo e espaço. O acesso é automático, os resultados das pesquisas estão disponíveis para o mundo.

Outro fator interessante do sistema é a redução de custos para as revistas e também para o usuário. O leitor busca as publicações na rede, o SEER propicia incentivar o acesso aberto das publicações científicas.

A publicação eletrônica reforça a função primordial de divulgação de informações científicas, mediante a utilização de recursos tecnológicos e financeiros, que fazem decrescer os custos dos periódicos, pelo menos no que se refere à impressão e distribuição. (DIAS; GARCIA, 2008, p. 4).

$\mathrm{Na}$ atualidade há um crescente número de periódicos eletrônicos que visam facilitar o acesso e uso das publicações científicas, além de atender de forma satisfatória as necessidades das instituições brasileiras.

Sendo os periódicos científicos propulsores do crescimento e disseminação do conhecimento no Brasil e no mundo, passaram e continuam a passar por modificações, reestruturações e adaptações a partir de avanços tecnológicas presentes em cada época. (FACHIN; HILLESHEIM, 2006, p. 32).

A comunicação científica cresce à medida que aumentam as publicações, e as tecnologias proporcionam que essas publicações sejam lidas, analisadas e discutidas entre os pares e o conhecimento seja socializado. Para Sant'ana e Santos (2004, p. 55), "quanto mais os comunicadores compartilharem conhecimentos similares, experiências e conhecimentos anteriores, maior será a eficiência da comunicação por canais de mediação digital."

O SEER pode ser visto como um facilitador da comunicação científica na internet, visto que oferece ferramentas para o gerenciamento dos periódicos científicos.

O SEER faz parte da nova geração de sistemas de gerenciamento de periódicos científicos e, no Brasil, ele surge como modelo alternativo de publicação do conhecimento científico para ampliar o acesso, a preservação e o impacto das pesquisas e dos resultados daí provenientes. (ARELLANO; SANTOS; FONSECA, 2005).

O Open Jornal System, conhecido no Brasil como Sistema Eletrônico de Editoração, está on-line, acompanha as inovações tecnológicas, propicia publicações em revistas qualificadas que aderiram ao sistema, as quais passam pelas mesmas avaliações que as revistas impressas, além de preocupar-se com as normas de publicações e direitos autorais.

Valério e Pinheiro (2008, p. 160) discutem que "avanços na ciência e tecnologia brindam-nos com a comunicação eletrônica que, por sua vez avança para conexões em redes, ligando espaços virtuais infinitos, aproximando territórios e indivíduos”. O SEER está sendo difundido nacional e internacionalmente, e os recursos tecnológicos, as iniciativas das 
instituições de visualizar suas publicações, além da liberdade de uso do sistema, contribuem para esse crescimento.

Com os avanços tecnológicos e a diminuição das barreiras relacionadas à utilização e aceitação dos recursos eletrônicos por autores, leitores e editores, as revistas eletrônicas na $\mathrm{Web}$ surgiram como uma alternativa para aumentar a rapidez na disseminação e ampliar a distribuição da informação entre os cientistas, mantendose os critérios de qualidade. (FERREIRA; CAREGNATO, 2008, p. 172).

A visualização ampla das revistas incentiva as diversas instituições a buscarem o sistema para gerir suas publicações; os recursos on-line contribuem para que os editores economizem tempo, custos e mão de obra, visto que o processo está mais dinâmico e menos dependente de pessoas, isto é, a editoração até então - no modelo impresso, em que o autor enviava cópias aos editores, estes encaminham aos avaliadores, e o processo se repetia em ordem inversa até a publicação do trabalho na revista - colaborava para a morosidade do trabalho. Com o SEER, a editoração acontece pelo sistema, não há impressões, nem envio via correios.

O autor define a revista, submete seu trabalho e acompanha o desenvolvimento da editoração sem depender de tempo ou local. A resposta dos avaliadores tende a ocorrer em menor tempo, e, com esse fator, a publicação final do trabalho acontece rapidamente, e ele fica visível on-line.

O sistema também coopera para reduzir custos para as instituições públicas, pois as editoras diminuem as publicações impressas. Para Souza (2004, p. 141), “o suporte eletrônico apresentou-se como uma oportunidade para as universidades recuperarem os seus direitos autorais e reduzirem gastos".

Compreende-se que o SEER, além de contribuir para as publicações eletrônicas, difunde os movimentos de acesso aberto, que origina proveitos para a sociedade em geral, e rompe barreiras de tempo e espaço.

\section{METODOLOGIA}

Entende-se a importância de se realizarem pesquisas com o envolvimento de pessoas que buscam novos conhecimentos e contribuem para o desenvolvimento intelectual do país. Para Marconi e Lakatos (2005, p. 157), “pesquisa é um procedimento formal, com método de pensamento reflexivo, que requer um tratamento científico e se constitui no caminho para conhecer a realidade ou para descobrir verdades parciais". 
Para o desenvolvimento do trabalho, realizou-se pesquisa exploratória, investigativa e quantitativo-descritiva. Foram selecionados documentos publicados em revistas de biblioteconomia que discutissem o SEER, quantificados os dados encontrados e analisados os resultados.

A busca pelas revistas foi realizada no site do Instituto Brasileiro de Informação em Ciências $\mathrm{e}$ Tecnologia

(IBICT), $<$ http://seer.ibict.br/index.php?option=com_mtree\&Itemid=109>. Como critérios de seleção, destacam-se revistas de Biblioteconomia que utilizam o SEER, revistas correntes e em língua portuguesa.

Foram utilizados suportes, como artigos, relatos de experiência, estudo de caso, entre outros. A seleção do conteúdo foi feita nas próprias revistas, no campo pesquisa simples, e não se limitou a título, autor ou resumo. As palavras-chave usadas para realização das pesquisas foram SEER, OJS, SEER and acesso aberto, SEER and acesso livre e SEER and Brasil.

Para o embasamento do trabalho, referenciam-se autores que discutem editoração eletrônica, tecnologias, acesso livre e comunicação científica, como Meadows (1999), Vidotti e Vieira (2004), Fachin e Hillesheim (2006), Targino (2007), Ferreira e Caregnato (2008), Leite (2009), entre outros.

\section{ANÁLISE E DISCUSSÃo DOS RESULTADOS}

A busca realizada no IBICT recuperou 30 informações que referenciam o termo Biblioteconomia, entre as quais, encontram-se notícias sobre o SEER, revistas do Conselho Regional de Biblioteconomia (CBR), revistas com suas edições já encerradas e revistas com idioma em inglês. Após análise, selecionaram-se 18 revistas eletrônicas para coleta de dados.

Para a discussão dos resultados, demonstram-se as revistas recuperadas, as instituições às quais pertencem, as edições e o ano que passaram a usar o SEER para publicarem seus documentos. Procura-se demonstrar que, mesmo o sistema sendo relativamente novo, as instituições estão aderindo a ele e inovando com o processo de editoração eletrônica. 


\begin{tabular}{|c|c|c|c|}
\hline Revistas de Biblioteconomia & Instituição & Edição & $\begin{array}{l}\text { Início do } \\
\text { Periódico no } \\
\text { SEER }\end{array}$ \\
\hline BIBLIONLINE & $\begin{array}{c}\text { Universidade Federal da Paraíba - } \\
\text { UFP } \\
\text { João Pessoa/PB }\end{array}$ & 2005 - - & 2007 \\
\hline $\begin{array}{l}\text { BIBLOS: Rev. do Departamento de } \\
\text { Biblioteconomia e História }\end{array}$ & $\begin{array}{l}\text { Universidade Federal do Rio } \\
\text { Grande - FURG } \\
\text { Rio Grande/RS }\end{array}$ & 1985 - - & 2007 \\
\hline Ciência da Informação & $\begin{array}{c}\text { Instituto Brasileiro de Informação } \\
\text { em Ciência e Tecnologia - IBICT } \\
\text { Brasília/DF }\end{array}$ & 1972 - - & 2004 \\
\hline Em Questão & $\begin{array}{l}\text { Universidade Federal do Rio } \\
\text { Grande do Sul - UFRGS } \\
\text { Porto Alegre/RS }\end{array}$ & $2003--$ & 2007 \\
\hline $\begin{array}{l}\text { Encontros Bibli: Revista Eletrônica de } \\
\text { Biblioteconomia e Ciência da Informação }\end{array}$ & $\begin{array}{l}\text { Universidade Federal de Santa } \\
\text { Catarina - UFSC } \\
\text { Florianópolis/SC }\end{array}$ & $1996--$ & 2007 \\
\hline ETD - Educação Temática Digital & $\begin{array}{l}\text { Universidade Estadual de } \\
\text { Campinas - Unicamp } \\
\text { Campinas/SP }\end{array}$ & $1999--$ & 2004 \\
\hline Informação \& Informação & $\begin{array}{c}\text { Universidade Estadual de Londrina } \\
\text { - UEL } \\
\text { Londrina/PR }\end{array}$ & $1996--$ & 2006 \\
\hline Informação \& Sociedade: Estudos & $\begin{array}{c}\text { Universidade Federal da Paraíba - } \\
\text { UFPB } \\
\text { João Pessoa/PB }\end{array}$ & 1991 - - & 2004 \\
\hline PerCursos & $\begin{array}{l}\text { Universidade do Estado de Santa } \\
\text { Catarina - UDESC } \\
\text { Florianópolis/SC }\end{array}$ & $2000--$ & 2006 \\
\hline Perspectivas em Ciência da Informação & $\begin{array}{c}\text { Universidade Federal de Minas } \\
\text { Gerais - UFMG } \\
\text { Belo Horizonte/MG }\end{array}$ & $1996--$ & 2005 \\
\hline $\begin{array}{l}\text { Pesquisa Brasileira em Ciência da Informação e } \\
\text { Biblioteconomia }\end{array}$ & $\begin{array}{c}\text { Instituto Brasileiro de Informação } \\
\text { em Ciência e Tecnologia - IBICT } \\
\text { Rio de Janeiro/RJ }\end{array}$ & $\begin{array}{c}2006- \\
2008\end{array}$ & 2006 \\
\hline$\underline{\text { PontodeAcesso }}$ & $\begin{array}{c}\text { Universidade Federal da Bahia - } \\
\text { UFBA } \\
\text { Salvador/BA }\end{array}$ & $2007--$ & 2007 \\
\hline Revista ACB: Biblioteconomia em Santa Catarina & $\begin{array}{l}\text { Associação Catarinense de } \\
\text { Bibliotecários - ACB } \\
\text { São José/SC }\end{array}$ & $1996--$ & 2005 \\
\hline $\begin{array}{l}\text { Revista Brasileira de Biblioteconomia e } \\
\text { Documentação: RBBD }\end{array}$ & $\begin{array}{c}\text { Federação Brasileira de } \\
\text { Associações de Bibliotecários - } \\
\text { FEBAB } \\
\text { São Paulo/SP }\end{array}$ & $2006--$ & 2006 \\
\hline$\underline{\text { Revista de Iniciação Científica da FFC }}$ & $\begin{array}{l}\text { Universidade Estadual Paulista } \\
\text { "Júlio de Mesquita Filho" - Unesp } \\
\text { Marília/SP }\end{array}$ & $2004--$ & 2004 \\
\hline $\begin{array}{l}\text { Revista Digital de Biblioteconomia e Ciência da } \\
\text { Informação }\end{array}$ & $\begin{array}{l}\text { Universidade Estadual de } \\
\text { Campinas - Unicamp } \\
\text { Campinas/SP }\end{array}$ & 2003 - - & 2004 \\
\hline $\begin{array}{l}\text { Revista Ibero-americana de Ciência da } \\
\text { Informacão: } \mathrm{RICl}=\text { Revista Iberoamericana de } \\
\text { Ciencias de la Información }\end{array}$ & $\begin{array}{l}\text { Universidade de Brasília - UnB } \\
\text { Brasília/DF }\end{array}$ & $\begin{array}{c}2008- \\
2008\end{array}$ & 2008 \\
\hline$\underline{\text { Transinformação }}$ & $\begin{array}{c}\text { Pontifícia Universidade Católica de } \\
\text { Campinas - PUC } \\
\text { Campinas/SP }\end{array}$ & 2002 - - & 2005 \\
\hline
\end{tabular}

Tabela1: Informações das revistas

Fonte: Os autores.

Ao observar a Tabela 1, entende-se que o Sistema Eletrônico de Editoração de Revistas inseriu-se nas diversas instituições, independente do espaço geográfico. Observa-se que, nos anos de 2004 e 2007, houve maior inserção de periódicos da Biblioteconomia no 
SEER. Destaca-se que, com o uso do SEER, as revistas deixam de ser locais ou regionais para serem conhecidas mundialmente.

Incluiu-se a edição do periódico e o ano em que ele foi inserido no sistema, para evidenciar que algumas revistas realizam a digitalização retrospectiva, isto é, incluem os artigos de edições antigas, em formato impresso. Exemplo é a revista Ciência da Informação, que tem edições desde 1972 e iniciou o uso do SEER no ano de 2004.

A tabela 2 demonstra as revistas pesquisadas com suas fontes, termo de busca, palavras-chave, artigos recuperados e os artigos selecionados. Nesta etapa cada revista eletrônica de biblioteconomia foi acessada. Realizaram-se buscas pelas palavras-chave, e os documentos recuperados foram analisados, separando os que atendiam à proposta do trabalho.

Acredita-se que, em outros periódicos de diferentes áreas do conhecimento, possa ser recuperado o tema SEER, mas a proposta do trabalho foi investigar as revistas de Biblioteconomia.

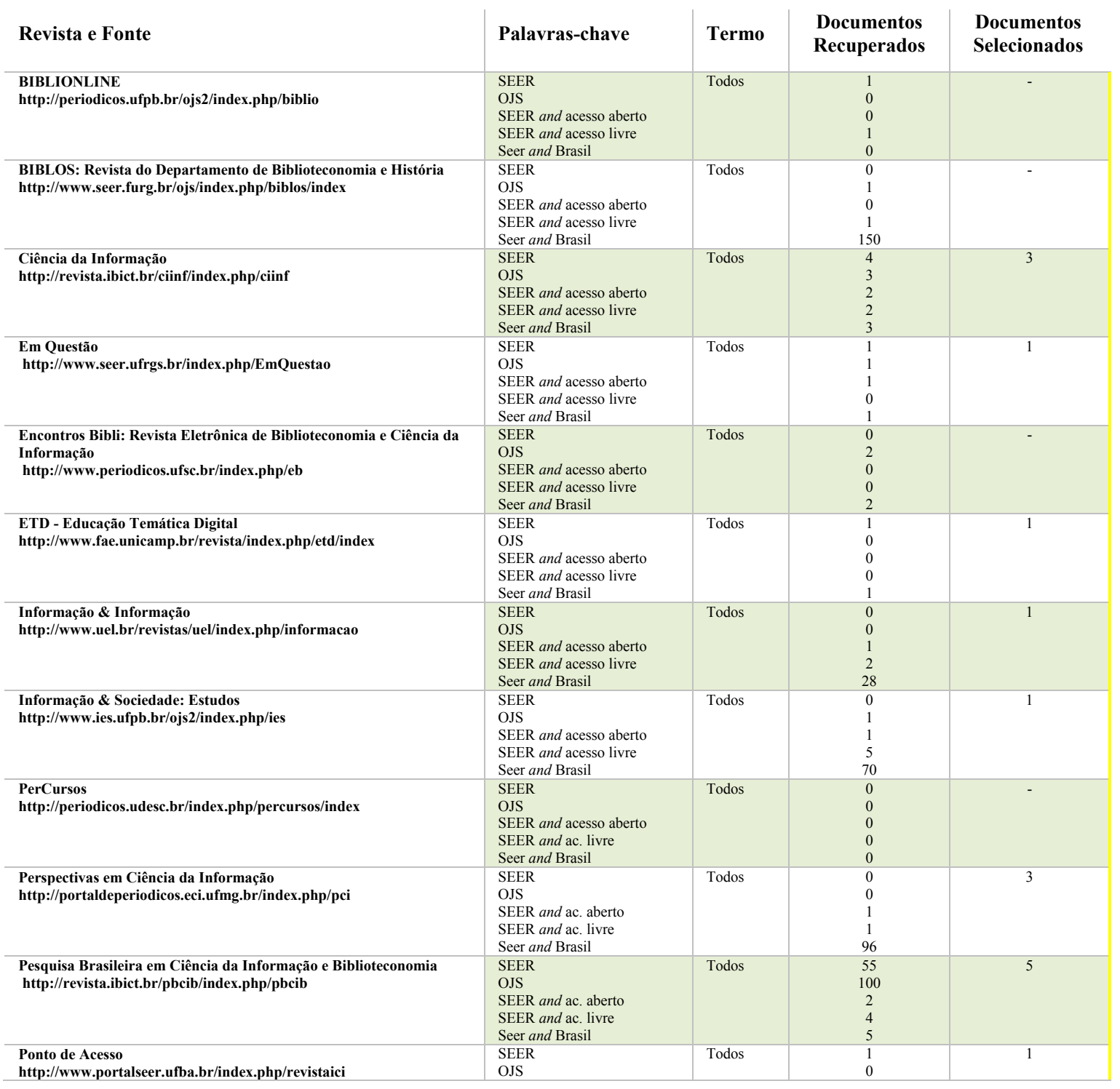




\begin{tabular}{|c|c|c|c|c|}
\hline & $\begin{array}{l}\text { SEER and } \text { ac. aberto } \\
\text { SEER and ac. livre } \\
\text { Seer } \text { and } \text { Brasil }\end{array}$ & & $\begin{array}{l}0 \\
0 \\
0\end{array}$ & \\
\hline $\begin{array}{l}\text { Revista ACB: Biblioteconomia em Santa Catarina } \\
\text { http://revista.acbsc.org.br/index.php/racb }\end{array}$ & $\begin{array}{l}\text { SEER } \\
\text { OJS } \\
\text { SEER and ac. aberto } \\
\text { SEER and } \text { ac. livre } \\
\text { Seer } \text { and } \text { Brasil }\end{array}$ & Todos & $\begin{array}{l}0 \\
0 \\
0 \\
0 \\
0\end{array}$ & - \\
\hline $\begin{array}{l}\text { Revista Brasileira de Biblioteconomia e Documentação: RBBD } \\
\text { http://www.febab.org.br/rbbd/ojs-2.1.1/index.php/rbbd/index }\end{array}$ & $\begin{array}{l}\text { SEER } \\
\text { OJS } \\
\text { SEER and ac. aberto } \\
\text { SEER and ac. livre } \\
\text { Seer } \text { and } \text { Brasil }\end{array}$ & Todos & $\begin{array}{l}1 \\
1 \\
0 \\
0 \\
0\end{array}$ & 1 \\
\hline $\begin{array}{l}\text { Revista de Iniciação Científica da FFC } \\
\text { http://www2.marilia.unesp.br/revistas/index.php/ric/index }\end{array}$ & $\begin{array}{l}\text { SEER } \\
\text { OJS } \\
\text { SEER and ac. aberto } \\
\text { SEER and } \text { ac. livre } \\
\text { Seer } \text { and } \text { Brasil }\end{array}$ & Todos & $\begin{array}{l}0 \\
0 \\
0 \\
0 \\
0\end{array}$ & - \\
\hline $\begin{array}{l}\text { Revista Digital de Biblioteconomia e Ciência da Informação } \\
\text { http://www.sbu.unicamp.br/seer/ojs/index.php }\end{array}$ & $\begin{array}{l}\text { SEER } \\
\text { OJS } \\
\text { SEER and ac. aberto } \\
\text { SEER and ac. livre } \\
\text { Seer } \text { and } \text { Brasil }\end{array}$ & Todos & $\begin{array}{l}0 \\
0 \\
0 \\
0 \\
0\end{array}$ & - \\
\hline $\begin{array}{l}\text { Transinformação } \\
\text { http://revistas.puc-campinas.edu.br/transinfo/index.php }\end{array}$ & $\begin{array}{l}\text { SEER } \\
\text { OJS } \\
\text { SEER and ac. aberto } \\
\text { SEER and ac. livre } \\
\text { Seer } \text { and } \text { Brasil }\end{array}$ & Todos & $\begin{array}{l}1 \\
1 \\
0 \\
0 \\
1\end{array}$ & 1 \\
\hline Total de documentos recuperados & - & - & 564 & 18 \\
\hline
\end{tabular}

Tabela 2: Dados da pesquisa

Fonte: Os autores

$\mathrm{Na}$ Tabela 2, visualiza-se que determinadas revistas não recuperam documentos, se a busca for feita por palavras-chave. Pode-se citar a Revista Digital de Biblioteconomia e Ciência da Informação, Revista de Iniciação Científica da FFC, PerCursos e Revista ACB: Biblioteconomia em Santa Catarina.

Observou-se inconsistência na indexação das revistas pesquisadas. Verificou-se repetição dos documentos com o uso das palavras, como SEER e OJS. Quando utilizado SEER and Brasil, foram recuperados documentos sobre o Brasil e não sobre o tema pesquisado. Após a análise dos documentos recuperados, no total de 564 documentos, foram excluídos as publicações até 2002, os documentos repetidos e certos tipos de documentos, como editoriais, carta de apresentação, entrevistas e resumos.

Destaca-se que o termo para a pesquisa não sofreu restrição, ou seja, não houve preferência por resumo, título, autores ou texto completo, preferiu-se buscar por todos os campos, para tornar a recuperação mais abrangente.

Ano

$2003-2004$

$2005-2006$

$2007-2008$

$2009-2010$

Total
Documentos relevantes

\begin{tabular}{|c|c|}
\hline 40 & 2 \\
\hline 144 & 6 \\
\hline 58 & 9 \\
\hline 40 & 1 \\
\hline 282 & 18 \\
\hline
\end{tabular}

Documentos selecionados

Tabela 3: Documentos recuperados e selecionados

Fonte: Os autores 
A Tabela 3 analisa os anos pesquisados, a quantidade de documentos relevantes e os selecionados para a pesquisa. Os documentos foram relacionados de dois em dois anos, e a seleção foi feita a partir de 2003, data em que começou a ser discutido o sistema no Brasil.

Observa-se que, nos anos de 2005 e 2006, ocorreu maior número de documentos recuperados. Já nos anos de 2007 e 2008, houve um melhor aproveitamento dos documentos selecionados. Ressalva-se que ainda há pouca discussão sobre as ferramentas do SEER, suas políticas, sua contribuição para sociedade, nota-se que as pesquisas sobre o sistema são, na sua maioria, referentes à parte prática de seu uso

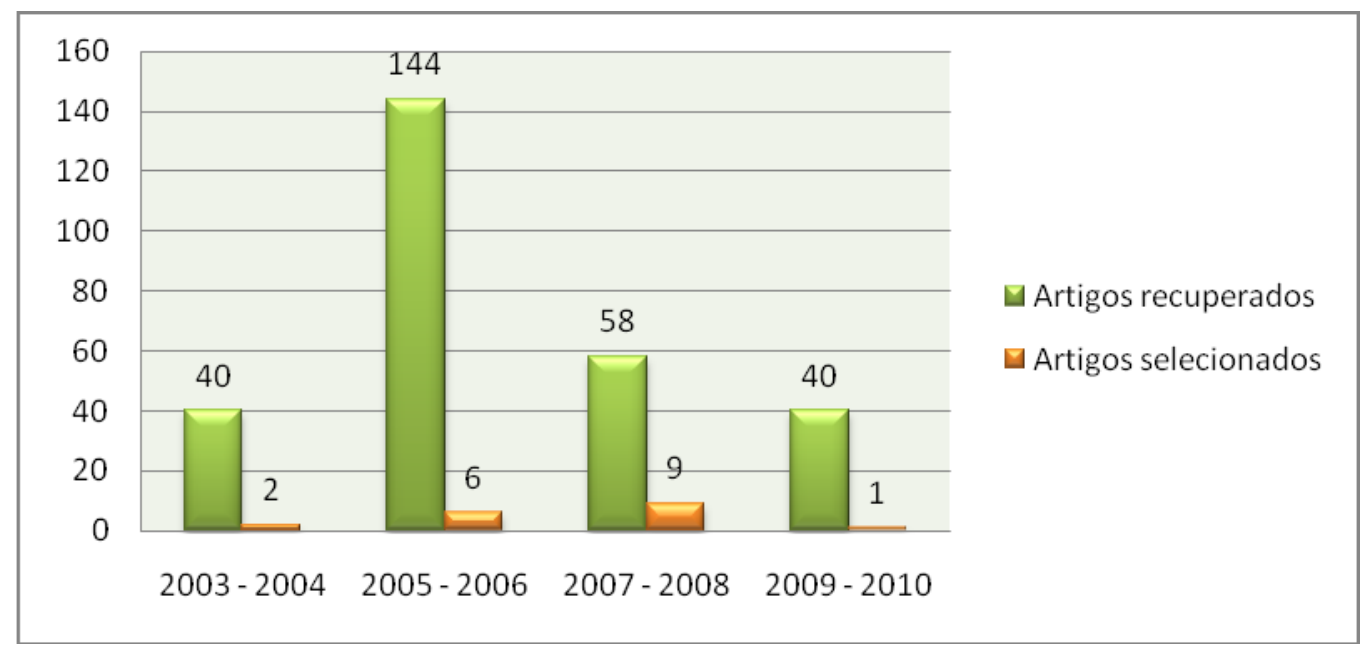

Figura 1:Documentos recuperados e selecionados

Fonte: Os autores

A Figura 1 busca enfatizar a diferença entre os documentos relevantes e os documentos selecionados. Compreende-se que os documentos relevantes são expressivos, porém, não foram contemplados, visto não discutirem assuntos pertinentes ao tema do trabalho.

Como a pesquisa aconteceu no âmbito das revistas de Biblioteconomia que utilizam o SEER, nada impede que outros documentos possam ser recuperados, independente da área do conhecimento, tanto em revistas eletrônicas como em repositórios, bases de dados e eventos.

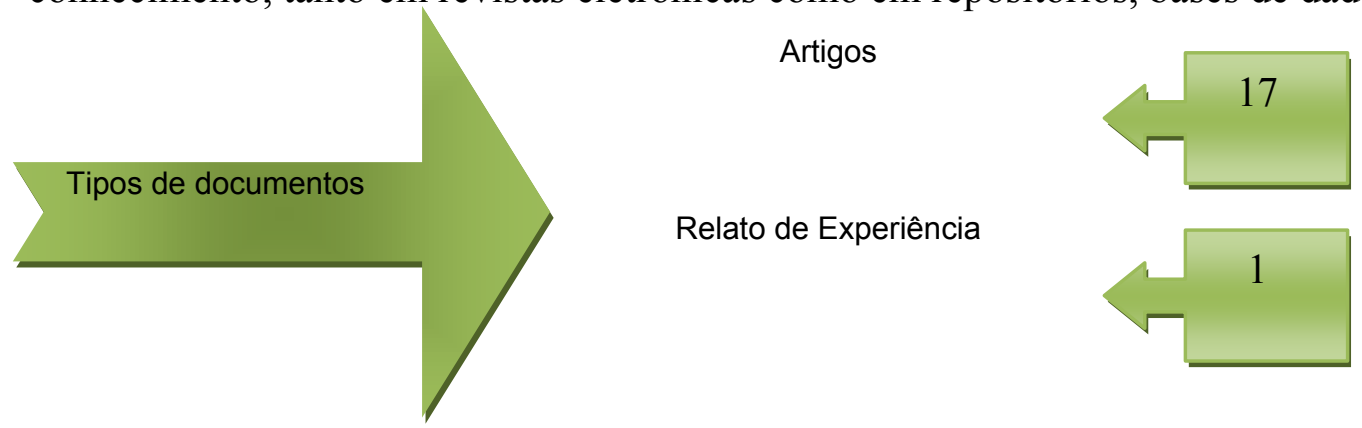

Figura 2: Tipos de documentos

Fonte: Os autores

A figura 2 tem por objetivo demonstrar, entre os documentos selecionados, a tipologia 
documental. Entre os 18 artigos selecionados, 17 são artigos científicos que colaboram para a divulgação do SEER, assim como sua implementação e ferramentas de uso, e um é um relato de experiência, que aborda de forma específica o SEER.

Como as revistas, em geral, são de cunho científico, os artigos fazem parte de suas rotinas. Nota-se que ocorrem publicações de outros tipos de documento, como os relatos de experiência, só que em menor quantidade.

Em geral, há uma grande preocupação em publicar, e cada pesquisador tem suas áreas específicas, o importante é que as publicações cheguem a todos os membros das academias e à sociedade em geral. O SEER propicia que isso aconteça de forma eficaz, promovendo qualidade para as revistas eletrônicas e confiança aos usuários que buscam na internet a comodidade de acessar a produção científica do país.

\section{CONSIDERAÇÕES}

Ao longo do trabalho, pôde-se constatar que as instituições estão aderindo ao Sistema Eletrônico de Editoração de Revistas (SEER). O processo de editoração está dinâmico, e a explicitação do conhecimento produzido a partir do uso do SEER contribui para a visibilidade dos autores e suas pesquisas.

O movimento de acesso aberto acontece mundialmente, fundamentado nas declarações de apoio e incentivo, como de Bethesda em 2003 e Budapeste em 2002, ao acesso às publicações científicas. A proposta do trabalho foi conhecer a produção do conhecimento sobre o SEER no Brasil, investigar, analisar e descrever os resultados encontrados.

Entende-se que os resultados encontrados foram escassos, entretanto, os artigos selecionados que abordam o sistema contemplam o assunto e colaboram com seu crescimento no Brasil. O uso do SEER coopera amplamente para que a comunicação científica aconteça livremente.As análises das publicações para o desenvolvimento do trabalho demonstram, entre outros assuntos, o compromisso que o IBICT assumiu ao incentivar que as instituições brasileiras usem o SEER para publicarem suas revistas no formato eletrônico.

Ao realizar a pesquisa nas revistas, a indexação apresenta pontos negativos, pois, ao serem usadas palavras com o operador booleano and, a recuperação apresentou somente resultados com uma palavra. Assim, todos os documentos tiveram de ser avaliados para que fossem selecionados os que atendessem a proposta do trabalho. Observa-se que, nas revistas 
de Biblioteconomia, poucos são os artigos que discutem o SEER, suas contribuições, sua funcionalidade e suas ferramentas.

As publicações científicas precisam ocorrer de forma exponencial; porém, deve-se primar pela qualidade de seus estudos. Mesmo no auge da explosão informacional, há necessidade de se obterem pesquisas sérias que passem pelo crivo da avaliação pelos pares e cooperem com demais estudos que ocorram posteriormente.

O SEER, visto como um gerenciador de publicações científicas que faz da tecnologia uma ferramenta para suas propostas, é valioso para a visibilidade das publicações científicas no Brasil.

\section{REFERÊNCIAS}

ARELLANO, M. M.; SANTOS, R.; FONSECA, R. SEER: disseminação de um sistema eletrônico para editoração de revistas científicas no Brasil. Arquivística.net, v.1, n.2. 2005. Disponível em: <http://www.arquivistica.net/ojs/viewarticle.php?id=33\&layout=abstract $>$. Acesso em: 15 de maio 2010.

DAVENPORT, Thomas H., PRUSAK, Laurence. Conhecimento empresarial: como as organizações gerenciam seu capital intelectual. 10 ed. Rio de Janeiro, Elsevier, 2003.

DIAS, G. A; GARCIA, J. C. R. Revistas científicas: financiamento, recursos tecnológicos e custos. In: FERREIRA, M. S. P. F.; TARGINO M. G.(org.). Mais sobre revistas científicas: em foco a gestão. São Paulo: SENAC, 2008. p.73-95

FACHIN, G. R. B.; HILLESHEIN A. I. A. Periódico científico: padronização e organização. Florianópolis: UFSC, 2006.

FERREIRA, A. G. C.; CAREGNATO, S. E. A editoração eletrônica de revistas científicas brasileiras: o uso de SEER/OJS. Transinformação, v.20, n.2. 2008. Disponível em: < $\mathrm{http}: / /$ revistas.puc-campinas.edu.br/transinfo/viewarticle.php?id $=227 \&$ locale $=\mathrm{fr}>$. Acesso em: 14 de maio 2010.

INSTITUTO BRASILEIRO DE INFORMAÇÃO EM CIÊNCIA E TECNOLOGIA.

Manifesto brasileiro de apoio ao acesso livre à informação científica.

Brasília: IBICT, 2005. Disponível em:

$<$ http://www.ibict.br/openaccess/arquivos/manifesto.htm>. Acesso em: 28 de maio 2010.

KURAMOTO, H. Informação científica: proposta de um novo modelo para o Brasil. Ciência da Informação, v.35, n.2, p.91-102. 2006. Disponível em: $<$ http://revista.ibict.br/ciinf/index.php/ciinf/article/view/831/678>. Acesso em: 19 de maio 2010.

LEITE, Fernando César Lima. Como gerenciar e ampliar a visibilidade da informação científica brasileira: repositórios institucionais de acesso aberto. Brasília: IBICT, 2009. 
MARCONI, M. A.; LAKATOS, E. M. Fundamentos da metodologia científica. 6 . ed. São Paulo : Atlas, 2005.

MEADOWS, A. J. A comunicação científica. Brasília: Briquet de Lemos, 1999

SANT'ANA, R. C. G.; SANTOS, P. L. V. A. C. Transferência de informação: análise de fatores para identificação do valor de unidades de conhecimento registrado. In: VIDOTTI, S. A. B. G. (coord.). Tecnologia e conteúdos informacionais. São Paulo: Polis, 2004.

SOUZA, M. F. S. Mudanças no processo de comunicação científica: a alternativa dos repositórios institucionais. In: VIDOTTI, S. A. B. G. (coord.). Tecnologia e conteúdos informacionais. São Paulo: Polis, 2004. p.139-151.

TARGINO, Maria das Graças. O óbvio da informação científica: acesso e uso. TRANSINFORMAÇÃO, Brasília, DF, 19.2, 0510 2007. Disponível em: $<$ http://revistas.puc-campinas.edu.br/transinfo/viewarticle.php?id=158>. Acesso em: $24 \mathrm{de}$ jun. 2010.

VALERIO, P. M.; PINHEIRO, L. V. R. Da comunicação científica à divulgação. TRANSINFORMAÇÃO, Brasília, DF，20.2， 0508 2008. Disponível em: $<$ http://revistas.puc-campinas.edu.br/transinfo/viewarticle.php?id=302>. Acesso em: 23 de abr. 2010.

VIDOTTI, Silvana Ap. B. Gregorio; VIEIRA, Telma A. Marques. O ambiente hipermídia no processo de construção do conhecimento. In: VIDOTTI, S. A. B. G. (coord.). Tecnologia e conteúdos informacionais. São Paulo: Polis, 2004. 